\title{
THE UNITY AND DIVERSITY OF THE SUBTERRANEAN REALM WITH RESPECT TO INVERTEBRATE BODY SIZE
}

\author{
Tanja Pipan ${ }^{1}$ and David C. Culver ${ }^{2 *}$
}

\begin{abstract}
A variety of subterranean habitats share an absence of light and a dependence on allochthonous productivity, but they differ in many features, including habitat volume. We examined the hypothesis that habitat volume is an important factor in community organization, especially with reference to body size, for a variety of communities for which data were available. We analyzed the results of ten studies that compared body sizes of obligate subterranean dwelling species with respect to habitat. All of the studies confirmed the hypothesis that habitat size was an important determinant of body size. However, surprisingly little information is available on the relationship between body size and habitat size, and only two of the studies reported directly on the size of habitat spaces. Habitat size appears to be an important determinant of body size in subterranean species, but more detailed studies, especially of habitat (pore) size are needed.
\end{abstract}

\section{BACKGROUND}

Scientists and naturalists have been aware of the subterranean realm and the often bizarre-appearing organisms that inhabit these habitats at least since the discovery, description, and subsequent availability of specimens of the European cave salamander Proteus anguinus in the eighteenth and nineteenth centuries (Aljančič et al., 1993; Shaw, 1999). The subterranean fauna, best known from caves, is strongly convergent, with obvious adaptations to subterranean life including elaboration of extra-optic sensory structures and loss of eyes and pigment (Culver et al., 1995). Subterranean habitats themselves are similar to each other in the sense that they share a complete absence of light (Culver and Pipan, 2014), a nearly universal dependence on spatial subsidies of organic carbon and nutrients (Fagan et al., 2007), and a reduction in environmental variability (Covington and Perne, 2015). At the same time, the subterranean environment is diverse, including both karst and other landscapes with caves and landscapes without caves. Racoviţă (1907) emphasized the importance of cracks and crevices in caves, rather than enterable cave passages as primary habitats for the "cave" fauna. A few biologists have even suggested that the entire cave fauna is really a fauna of cracks and crevices (Karaman, 1954). Since Racoviţă's essay, a number of other subterranean habitats, even in regions without caves, have been identified. Perhaps the most prominent non-cave subterranean habitat is the hyporheic, the underflow of rivers and streams (Malard et al., 2000), a habitat with its own unique fauna, including eyeless and depigmented species, that plays a critical role in the health and functioning of streams and rivers (Environmental Agency, 2009). Culver and Pipan (2014) identified a number of other shallow subterranean habitats occurring within a few meters of the surface. These include a variety of terrestrial habitats in the spaces and cracks in rocks, such as covered talus slopes, which are collectively given the name milieu souterrain superficiel (MSS) (Juberthie et al., 1980; Ortuño et al., 2013). Although rarely discussed with other subterranean habitats (but see Coiffait, [1958]), soil, especially deep soil, is also an aphotic habitat dependent on allochtonous production, also with a fauna with many eyeless and depigmented species. Still other habitats that harbor troglomorphic fauna, such as miniature perched drainage basins and their associated seepage spring exits (the hypotelminorheic of Messtrov [1962]), shallow calcrete aquifers found in arid regions of Australia (Humphreys, 2001), and termite mounds (Fenolio, 2016), are less well studied. There are also spaces deeper underground, including phreatic aquifers accessed by wells (Malard et al., 1997), deep caves more than $1 \mathrm{~km}$ in depth (Sendra and Reboleira, 2012), or mines that have specialized invertebrates (Fišer et al., 2014).

What has been largely neglected are both the unifying features of the subterranean realm beyond the obvious absence of light, and how different subterranean habitats can be quantified and ordered in a way that is important to the biology of the inhabitants. In this paper, we explore a potentially important organizing feature of the wide variety of subterranean habitats - habitat size, or pore volume. Habitat size is potentially a major determinant of maximum body size and shape because the space available, such as the spaces among rocks, can be the same order of magnitude in size as its inhabitants.

The extent to which the size of subterranean organisms is the result of the constraints of pore volume of the habitat may be true in a trivial sense. Fish do not live among sand grains (although they may temporarily bury themselves). There are also trivial ways in which this conjecture is false. No one expects beetles living in a cave passage $1 \mathrm{~m}$ in diameter to be smaller than the beetles living in a cave passages $10 \mathrm{~m}$ in diameter.

\footnotetext{
* Corresponding Author: dculver@american.edu

${ }^{1}$ Karst Research Institute at ZRC-SAZU, Titov trg 2, Postojna SI-6230, Slovenia, pipan@zrc-sazu.si

${ }^{2}$ Department of Environmental Science, American University, 4400 Massachusetts Ave. NW, Washington, DC 20016, USA
} 


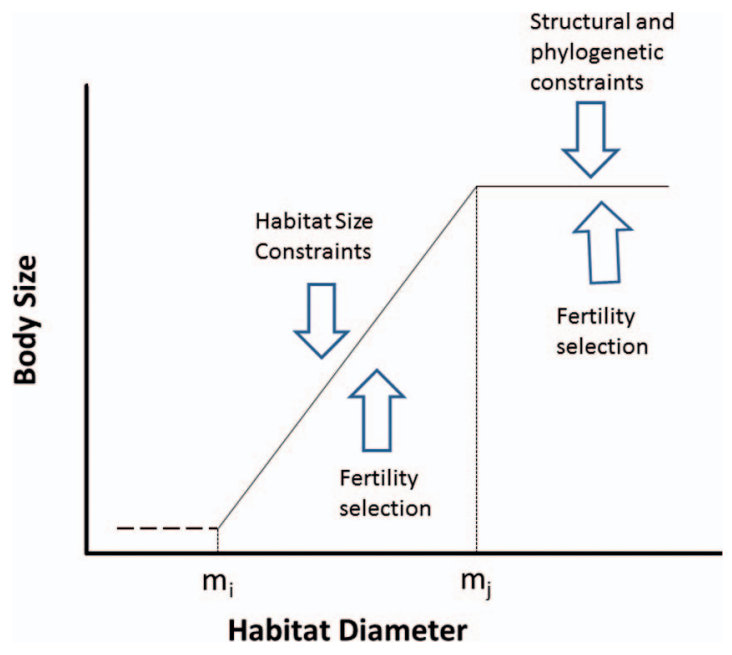

Figure 1. Hypothetical relationship between subterranean habitat diameter (pore size) and body size, with selective forces indicated by arrows. Below a minimum $\left(m_{i}\right)$, there is not sufficient space for animals to occur without burrowing. Above a maximum $\left(\mathrm{m}_{\mathrm{j}}\right)$, body size is likely constrained by other factors, such as phylogenetic and structural constraints. The relationship need not be linear but is presented as such for simplicity.

What is interesting is the possibility that for a range of habitat sizes, approximately $0.1 \mathrm{~mm}$ to $5 \mathrm{~cm}$, size is the result of two opposing sets of forces (Fig. 1). One force is the constraint of habitat size which limits body size, and the opposing forces are those selective forces that tend to increase body size: increased fecundity as a result of increased size (Culver et al, 1995; Fišer et al., 2013), escape from predation (Jones et al., 1992), and storage of nutrients of larger subterranean invertebrates (Hüppop, 2000). Below a minimum pore diameter $\left(m_{i}\right.$ in Fig. 1$)$, there is not sufficient space for an organism to survive without moving the particles, and there is a maximum pore diameter $\left(\mathrm{m}_{\mathrm{j}}\right.$ in Fig. 1 ), above which no organism can be large enough to fill the pore volume.

Body size is a complex factor, subject to many selective pressures, including physiological factors like volume- surface area relationships (Sibley et al, 2012) and demographic factors like size-related fecundity (Kingsolver and Pfennig, 2004). One summary of body size selection is Cope's rule, that body size tends to increase within lineages (e.g., Alroy, 1998, but see Solow and Wang, 2008). The limit on the maximum size $m_{j}$ is the likely result of phylogenetic and developmental constraints. Our hypothesis is that the range of body sizes between $m_{i}$ and $m_{j}$ is determined by the habitat pore diameter, not physiological or ecological constraints.

Finally, we propose a placement of different subterranean habitats along this axis.

\section{Methods ANd Materials}

To examine the validity of the habitat size and depth axes, we surveyed the literature for data on the connection between body size and habitat size. We have made this survey as comprehensive as possible, but limited it to comparative studies. We included the following subterranean habitats (see Culver and Pipan [2014] for detailed discussion of habitat types): caves (aquatic and terrestrial), epikarst (aquatic), hyporheic and interstitial aquifers (aquatic), hypotelminorheic and seepage springs (aquatic), soil, and intermediate-size terrestrial subterranean habitats including the milieu souterrain superficiel (MSS) of Juberthie et al. (1980) and talus slopes.

For the connection between body size and habitat size, we consulted the publications listed in Table 1. Pore sizes were estimated by Culver and Pipan (2014), and in some cases, pore dimensions were given by the authors of the papers listed in Table 1.

Ideally, it would be possible to combine these studies into a meta-analysis (Borenstein et al., 2009), but the studies listed in Table 1 do not share enough in common, including statistical testing. Some analyze size without measurement of habitat size; some compare species among habitats; and a few compare body sizes and habitat sizes within a habitat type. For this reason, we can only provide a narrative, and not a statistical test.

Table 1. Literature consulted for relationship between habitat and body size.

Reference Subject

Arnedo et al. (2007)

Coineau (2000)

Culver and Ehlinger (1980)

Culver et al. (2009)

Culver et al. (2010)

de Bovée et al. (1995)

Ducarme et al. (2004)

Růžička (1998)

Trontelj et al. (2012)
Body sizes of Dysdera spiders in cave, surface, and MSS habitats

Within and between habitat comparison of body sizes of aquatic interstitial crustaceans Body sizes and gravel sizes of Caecidotea isopods in cave streams

Among habitat comparisons of copepod body sizes in epikarst and caves

Among habitat comparisons of Stygobromus amphipod sizes

Within habitat comparisons of body sizes of aquatic interstitial crustaceans

Comparison of body sizes of mites in soil and caves

Body sizes of Theonoe minutissima spiders in talus slopes and surface habitats Among habitat comparison of Niphargusamphipod sizes 


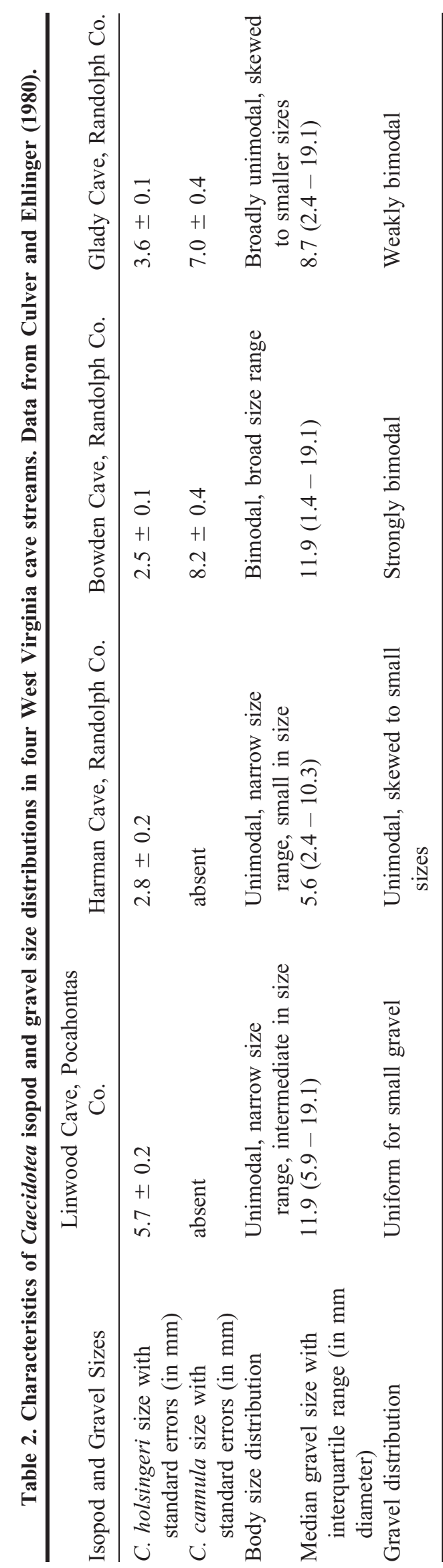

Results

Arnedo et al. (2007) analyzed body sizes in Dysdera spiders from lava tubes, MSS, and surface habitats in the Canary Islands, with pore diameters (not directly measured) largest in surface habitats and smallest in lava tubes. Phylogeny of Canary Island Dysdera is shown in Figure 2. When phylogenetic effects are taken into account and sister species are compared, a pattern of correlation between habitat and body size emerges. There are two MSS specialists, Dysdera madai and D. esquiveli. Dysdera madai is smaller ( $2.50 \mathrm{~mm}$ carapace length) than its sister species $D$. iguanensis $(3.12 \mathrm{~mm})$, primarily a surface dweller, but sometimes in MSS. D. esquiveli is the same size $(2.21 \mathrm{~mm})$ as a sister lavatube species (D. hernandezi, $2.18 \mathrm{~mm}$ ) but smaller than the ancestral surface species, D. brevisetae $(3.60 \mathrm{~mm})$. As far as lava-tube species, all six of the species except for $D$. hernandezi are larger, and in one case the same size, as their surface sister species. All in all, MSS species are smaller than surface dwellers while lava-tube species are larger, except for D. hernandezi.

Coineau (2000) noted that there were major size differences, more than an order of magnitude, between interstitial crustaceans and cave crustaceans. This is especially apparent in amphipods in the family Ingolfiellidae, where cave species range in size from 12 to $28 \mathrm{~mm}$ and species in interstitial sands reach only $1 \mathrm{~mm}$. She noted a strong correlation between particle size and size of a variety of crustaceans within interstitial habitats, with crustaceans reaching 1 to $3 \mathrm{~mm}$ long in sandy gravels, while those in sands are less than $1 \mathrm{~mm}$ long, although she did not quantify this relationship.

Culver and Ehlinger (1980) investigated the size distributions of both the Caecidotea isopods and the stream gravels they inhabit (Table 2). Size distribution of $C$. holsingeri and $C$. cannula paralleled that of the stream gravels. In the two caves with bimodal distribution of gravel sizes, both species occurred, and in the two caves with unimodal distributions of gravel sizes, only one species occurred (Table 2). When gravels were small, isopod sizes tended to be small. A remarkable feature of the system was the size plasticity of $C$. holsingeri, where adults ranged in size from 2.5 to $5.7 \mathrm{~mm}$. Culver and Ehlinger (1980) suggest that part of the reason for the match of gravel and body size is that washout rates from gravels, a source of mortality, is minimized when the size of isopods and gravels are matched. Fertility selection then presumably maximizes size within this constraint.

Culver et al. (2009) investigated possible differences in body sizes of different ecological groups of copepodsstygobionts known only from epikarst, stygobionts known from other subterranean habitats as well, and stygophiles, species known from surface habitats as well-found in drip waters (epikarst) of six Slovenian caves. The pore size of the epikarst habitat is small (Fairchild and Baker, 2012), for example a soda straw formation through which epikarst water exits has an outside diameter of approximately $5 \mathrm{~mm}$ (Curl, 1972). Culver et al. (2009) hypothesized that epikarst 


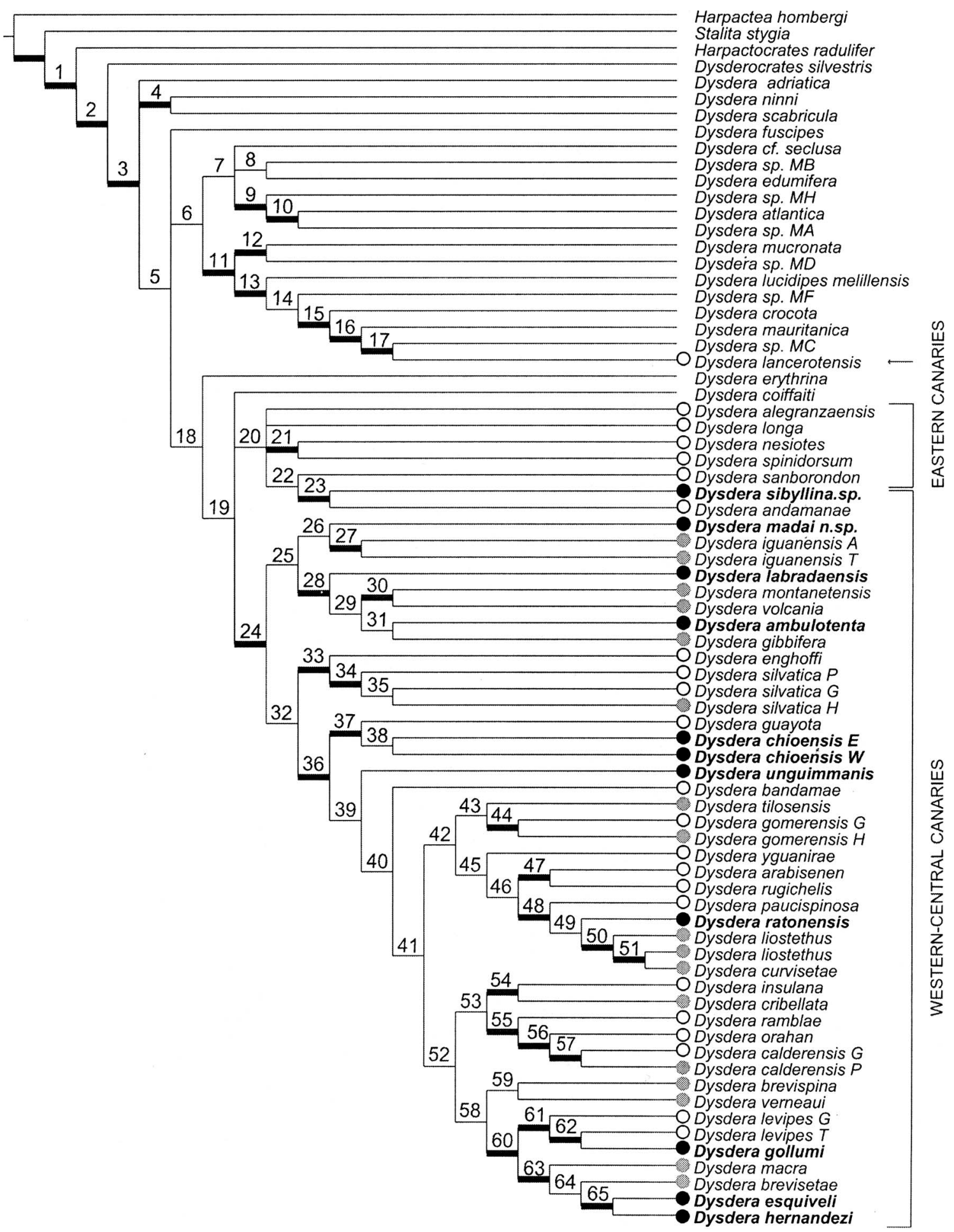

Figure 2. Strict consensus tree of the five most parsimonious trees for the spider genus Dysdera from the Canary Islands. Thick branches denote clades recovered under all alignment parameter cost combinations. Black dots identify trogloblionts, white dots refer to endemic Canarian species exclusively reported from epigean localities, and gray dots show epigean species also collected in subterranean habitats. From Arnedo et al. (2007). 
Table 3. Analysis of copepod size in relation to ecological classification, for all copepod sizes known from Slovenian caves. For HSD (honestly significant difference) groups, those not connected by the same letter are significantly different. For ANOVA, $\mathbf{F}_{2,52}=7.58, p<0.002$. From Culver et al. (2009).

\begin{tabular}{|c|c|c|c|c|}
\hline Group & $\mathrm{n}$ & $\begin{array}{l}\text { Mean } \\
(\mathrm{mm})\end{array}$ & S.E. & $\begin{array}{l}\text { Tukey-Kramer } \\
\text { HSD group }\end{array}$ \\
\hline Epikarst stygobionts & 4 & 0.495 & 0.061 & $\mathrm{a}$ \\
\hline Other stygobionts & 25 & 0.652 & 0.045 & $\mathrm{~b}$ \\
\hline Stygophiles & 26 & 0.93 & 0.071 & $b$ \\
\hline
\end{tabular}

specialists would be smaller than more generalist species because of pore-size constraints, and in fact, they did find that stygobionts in epikarst were smaller than other species living in epikarst (Table 3 ).

Culver et al. (2010) looked for correlations between habitat size and body size for the amphipod genus Stygobromus. They found that median body sizes for Stygobromus in the four habitats ranged from $9 \mathrm{~mm}$ in cave streams to $5.4 \mathrm{~mm}$ in epikarst (Fig. 3). Hypotelminorheic and phreatic species were intermediate in size. This is in accord with the relative pore size of the habitat, with the possible exception of phreatic habitats, about which we know little, but are likely variable in pore size. The variability of body sizes within a habitat probably is the result not only of pore size differences but competition among species as well. Additionally, there may be a tradeoff between size and shape, such that large amphipods may be narrower. However, Culver et al. (2010) found no differences in shape, as measured by relative antennal size, for different-size habitats.

In a study in Morocco, de Bovée et al. (1995) examined the relationship between amphipods and isopods and granulometry of sediments in two rivers in the High Atlas mountains. They noted that silt in the sediment usually excluded amphipods and isopods (see Fig. 1), and both isopod and amphipod species typically were found in gravels as opposed to clay and sand. They suggest that the amphipod and isopod species may be further subdivided in the habitat by finer differences in sediment size, but they present no direct evidence on this point.

Ducarme et al. (2004) compared body sizes of mites in deep soil and caves in Belgium. The largest cave species was Veigaia paradoxa $(1065 \mu \mathrm{m})$, and the largest deep-soil species was Leptogamasus suecicus $(610 \mu \mathrm{m}$, Table 4$)$. In all seven families with both deep soil and caves representatives, all the cave species within a family were larger than all the deep soil species within a family. The maximum size is likely set in part by phylogenetic constraints.

Růžička (1998) compared body lengths of the spider Theonoe minutissima in peat bogs and talus slopes, the latter being a shallow subterranean habitat. The subterranean populations in talus slopes were larger than the surface dwelling populations in peat bogs by about 10 percent.

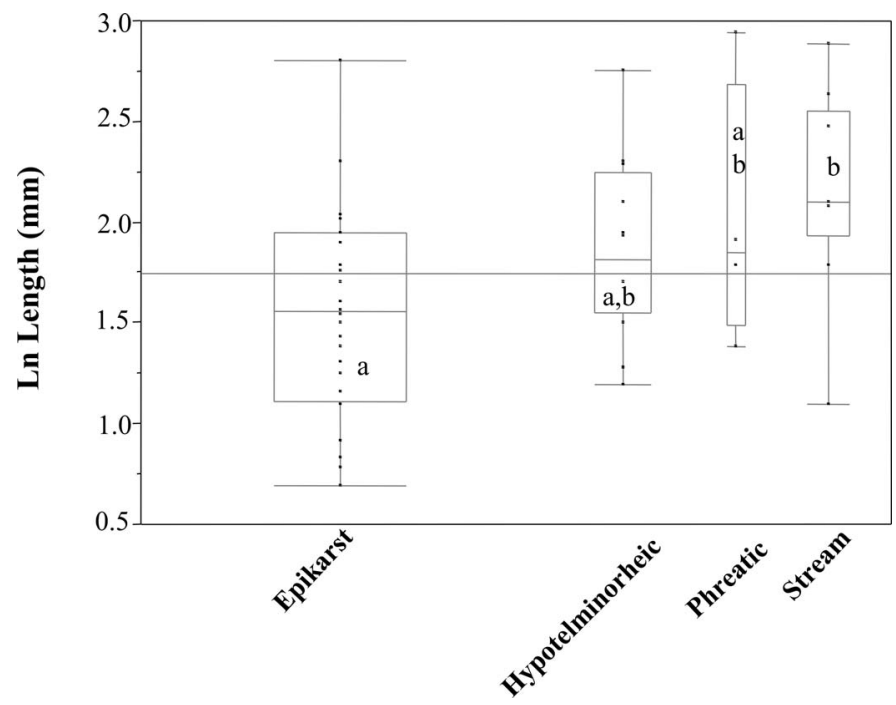

Figure 3. Box and whiskers plots of In female body length of species of the amphipod genus Stygobromus for epikarst, hypotelminorheic, cave streams, and phreatic habitats in North America. The overall mean is represented by the line across the entire figure. Boxes contain 50 percent of the data points; the line across each box is the group median; the whiskers show minimum and maximum values. The widths of the rectangles are proportional to sample size. Dots are individual data points. Plots with the same letter (a or b) do not differ according to the TukeyCramer HSD test. From Culver et al. (2010).

Presumably, pore sizes are larger in talus with its many rocks than in peat bogs, largely composed of fine sediments.

Trontelj et al. (2012) also found that the body size of Niphargus amphipods from species-rich cave communities of the Dinaric karst of central and southeastern Europe was correlated with pore size. They compared species from four habitats within or directly connected to caves, epikarst, cave interstitial, phreatic, and cave stream. Small-pore interstitial and epikarst was represented by the ecomorph they called small pore. Large-pore phreatic and cave streams were represented by four ecomorphs, cave stream, cave lake, lake giants, and daddy-longlegs (Fig. 4). The four large-pore ecomorphs were also distinguished by different shapes in their figure. As in Culver et al.'s (2010) study, phreatic species were somewhat enigmatic, represented by three distinct ecomorphs.

\section{DisCUSSION}

Overall, there is a match between habitat size and organism size, as predicted (Fig. 1), and there seems to be a tradeoff between environmental constraints (in terms of pore size) and the benefits (in terms of reproductive fitness) of being large. However, the data available for analysis are not entirely satisfactory. In particular, relatively little attention has been 


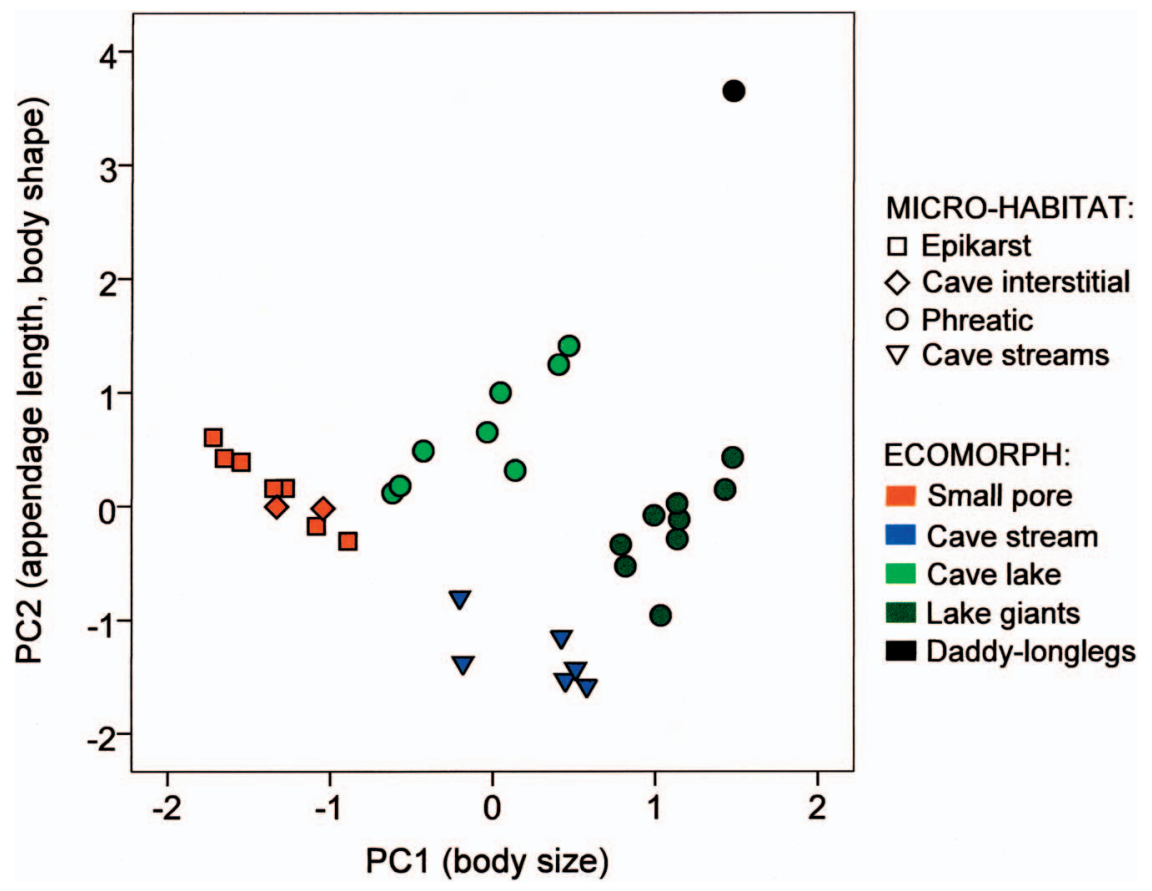

Figure 4. Principal Components Analysis on morphometric traits (mean values) of 33 Niphargus species and populations from seven cave communities in the Dinaric karst. The first two axes (PC1 and PC2) together explain 97.5 percent of the total variation. The first principal component is body length only, and accounts for 72.4 percent of the total variation. Cave microhabitats (symbols) and proposed ecomorphs (colors) are only partly in agreement. There is no morphological distinction between inhabitants of the epikarst and the cave interstitial, and there are three distinct morphological groups within the phreatic habitat. From Trontelj et al. (2012).

Table 4. Average body size (in $\mu \mathrm{m}$ ) for deep soil and cave mite indicator species in Belgium. Adapted from Ducarme et al. (2004).

\begin{tabular}{|c|c|c|c|c|}
\hline \multirow[b]{2}{*}{ Family } & \multicolumn{2}{|c|}{ Deep Soil } & \multicolumn{2}{|c|}{ Caves } \\
\hline & Species & Body Length & Species & Body Length \\
\hline \multicolumn{5}{|c|}{ Rhodacaridae } \\
\hline & Rhodacarellus apophyseus & 366 & Rhodacarus aequalis & 588 \\
\hline & & & Rhodacarus agrestis & 645 \\
\hline \multicolumn{5}{|c|}{ Parasitidae } \\
\hline & Leptogamasus suecicus & 610 & Vulgarogamasus sp. & 1053 \\
\hline \multicolumn{5}{|c|}{ Veigaiidae } \\
\hline & Veigaia exigua & 491 & Veigaia paradoxa & 1065 \\
\hline \multicolumn{5}{|c|}{ Eupodidae } \\
\hline & Claveupodes sp. & 227 & Benoinyssus ereynetoides & 285 \\
\hline & Cocceupodes sp. & 281 & & \\
\hline \multicolumn{5}{|c|}{ Rhagidiidae } \\
\hline & Shibala longisensilla & 583 & Poecilophysis spelaea & 1033 \\
\hline & Hammenia macrostella & 309 & & \\
\hline \multicolumn{5}{|c|}{ Tydaeoidae } \\
\hline & Tydaeolus sp. & 154 & Riccarodoellinae sp. & 465 \\
\hline & Coccotydaeolus sp. & 154 & & \\
\hline & Sellnickochthonius facoti & 148 & Liochthonius leptaleus & 197 \\
\hline & & & Liochthonius propinquus & 180 \\
\hline & & & Liochthonius strenzkei & 220 \\
\hline
\end{tabular}



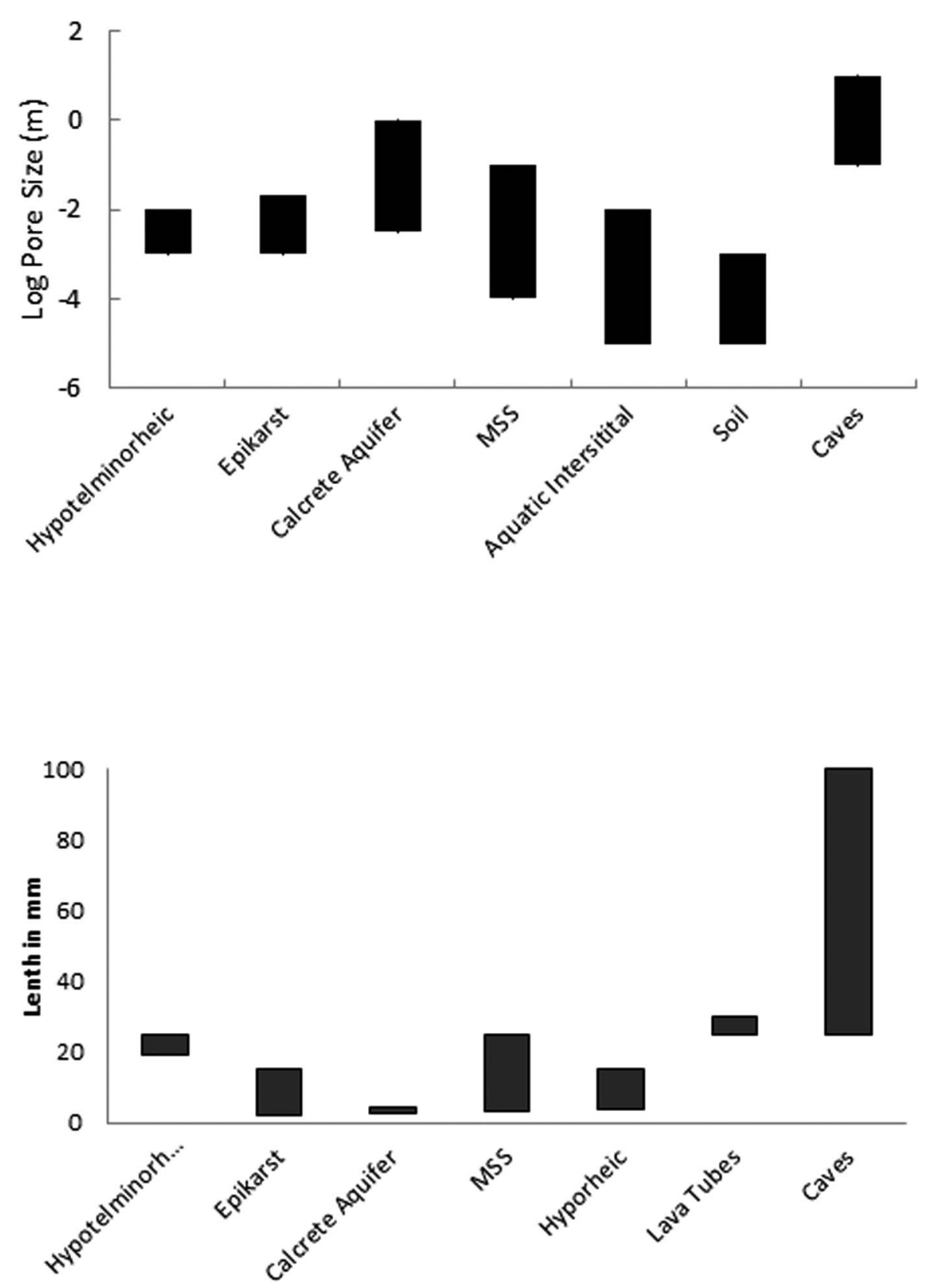

Figure 5. Histograms of body lengths of inhabitants and log of pore size for different subterranean habitats.

paid to the actual pore size of subterranean habitats, the exceptions being Culver and Ehlinger (1980) and de Bovée et al. (1995). Pore size can be determined from particle size as well, at least for uniformly sized particles. For example, a sphere with a diameter of $0.828 r$ can be inserted into a uniformly packed volume of sediments of radius $r$. Culver and Pipan (2014) provided some general estimates of pore size for different subterranean habitats, and overall the sizes of organisms in these habitats seem to match pore size (Fig. 5).

Only two of the studies explicitly took into account phylogenetic effects (Arnedo et al., 2007; Trontelj et al, 2012), although most other studies limited comparisons to within genera or families. The studies did encompass a wide variety of taxonomic groups, including both aquatic (Amphipoda, Copepoda, Isopoda) and terrestrial (Araneae, Acari) and encompassed a number of different subterranean habitats, including caves, lava tubes, interstitial habitats, talus slopes, epikarst, and milieu souterrain superficiel.

Body length itself is but one measure of the habitat dimensions needed by an organism. In an elegant study of some Niphargus amphipods, Delić et al. (2016) showed that both water velocity and the presence of competitors had a major effect on relative lengths of antennae and pereopods, but a small effect on body size. Overall thinning and 
elongation of the body can occur as well, and it is carried to an extreme in some deep-soil mites such as Gordialycus tuzetae, which is nearly $3 \mathrm{~mm}$ long and only $0.05 \mathrm{~mm}$ wide (Thibaud and Coineau, 1998). Differences in overall shape of organisms are approximated by Principal Components Analysis as well as other multivariate analyses. Such analyses are likely to be informative in the present context (e.g., Trontelj et al., 2012. Given the fundamental connection between habitat size and organism size, it is curious that this connection is less well studied than the effect of competition on body size (Vergnon et al., 2013). Their study illustrates this very clearly; the ratio of body sizes of dytisicid beetles in calcrete aquifers (1.3:1) is that predicted by the theory of limiting similarity (MacArthur and Levins, 1967). But the overall sizes of the beetles vary from aquifer to aquifer, possibly the result of different pore sizes in different habitats, but there is no data on granulometry of these habitats.

In addition to habitat (pore) size, several other parameters are likely to be useful in ordinating subterranean communities. Communities in different subterranean habitats, such as caves, talus slopes, and soil, differ in species richness and in the frequency of troglomorphy among the resident species (see Pipan and Culver, 2012; Culver and Pipan, 2015). Subterranean habitats themselves vary along several important parameters, including percent organic matter and connectivity to the surface (Culver and Pipan, 2014), and water velocity (Delić et al., 2016). These habitats and their associated communities can be ordered along an axis of depth, a proxy for amount of organic matter and connection to surface habitats, and species richness of communities, as well as the degree of specialization of the component species, can then be compared to depth. Together with pore size, depth is likely to prove to be an important organizing principle for the variety of subterranean communities. While clearly not a substitute for the naming and description of different subterranean habitats, it is a way to consider the unity of subterranean habitats.

\section{Conclusions}

The role of habitat size in determining body size is far from trivial. For a range of habitat sizes, the size of the invertebrates occupying the habitat seems to approach some maximum for that habitat, unless there are competing species that further affect body size. The reasons that body size is maximized within the constraints of habitat size are likely twofold. First, larger subterranean animals have larger eggs and higher fecundity (Fišer et al., 2013), resulting in natural selection in favor of increased body size (Jones et al., 1992). Second, the absence of large predators reduces or eliminates the selective pressure toward smaller body size caused by predation. In cases where body size does not appear to be maximized, interspecific competition has been strongly implicated (Trontelj et al., 2012; Vergnon et al., 2013).

\section{AcKNOWLEDGEMENTS}

This project was supported by funds from funds from Slovenian Research Agency (BI-US/15-16-077) and the Mellon Fund of the College of Arts and Sciences, American University. Cene Fišer and Daniel Fong read an earlier version of this paper and made a number of useful suggestions.

\section{REFERENCES}

Aljančič, M., Bulog, B., Kranjc, A., Josipovič, D., Sket, B., and Skoberne, P., 1993, Proteus: the Mysterious Ruler of the Karst Darkness: Ljubljana, Slovenia, Vitrum, $75 \mathrm{p}$.

Alroy, J., 1998, Cope's rule and the dynamics of body mass evolution in North American fossil mammals: Science, v. 280, p. 731-734. https://doi.org/10. 1126/science.280.5364.731.

Arnedo, M.A., Oromí, P., Múrria, C., Macías-Hernández, N., and Ribera, C., 2007, The dark side of an island radiation: systematics and evolution of troglobitic spiders of the genus Dysdera Latreille (Araneae, Dysderidae) in the Canary Islands: Invertebrate Systematics, v. 21, p. 623-660. https:// doi.org/10.1071/IS07015.

Borenstein, M., Hedges, L.V., Higgins, J.P.T., and Rathski, A.R., 2009, Introduction to Meta-Analysis: West Sussex, U.K., John Wiley and Sons, $420 \mathrm{p}$.

Coiffait, H., 1958, Les coléoptères du sol: Vie et Milieu Supplement, v. 7, 204 p.

Coineau, N., 2000, Adaptations to interstitial groundwater life, in Wilkens, H., Culver, D.C., and Humphreys, W.H., eds., Subterranean Ecosystems: Amsterdam, The Netherlands, Elsevier, p. 189-206.

Covington, M.D., and Perne, M., 2015, Consider a cylindrical cave: a physicist's view of cave and karst science: Acta Carsologica, v. 44, p. 363-380. doi:10.3986/ac.v44i3.1925.

Culver, D.C., and Ehlinger, T.J., 1980, The effects of microhabitat size and competitor size on two cave isopods: Brimleyana, v. 4, p. 103-113.

Culver, D.C., Holsinger, J.R., Christman, M.C., and Pipan, T., 2010, Morphological differences among eyeless amphipods in the genus Stygobromus dwelling in different subterranean habitats: Journal of Crustacean Biology, v. 30, p. 68-74. https://doi.org/10.1651/09-3156.1.

Culver, D.C., Kane, T.C., and Fong, D.W., 2005, Adaptation and Natural Selection in Caves. The Evolution of Gammarus minus: Cambridge, Mass., Harvard University Press, 223 p.

Culver, D.C., Pipan, T., and Schneider, K., 2009, Vicariance, dispersal and scale in the aquatic subterranean fauna of karst regions: Freshwater Biology, v. 54, p. 918-929. https://doi.org/10.1111/j.1365-2427.2007. 01856.x.

Culver, D.C., and Pipan, T., 2009, Biology of Caves and Other Subterranean Habitats: Oxford, England, Oxford University Press, Biology of Habitats Series, $254 \mathrm{p}$.

Culver, D.C., and Pipan, T., 2014, Shallow Subterranean Habitats. Ecology, Evolution, and Conservation: Oxford, England, Oxford University Press, Biology of Habitats Series, $258 \mathrm{p}$.

Culver, D.C., and Pipan, T., 2015, Shifting paradigms in the evolution of cave life: Acta Carsologica, v. 44, p. 415-425. https://doi.org/10.3986/ac.v44i3. 1688.

Curl, R.L., 1972, Minimum diameter stalactites: Bulletin of the National Speleological Society, v. 34, p. 129-136.

de Bovée, F., Yacoubi-Khebiza, M., Coineau, N., and Boutin, C., 1995, Influence du substrat sur la réparition des Crustacés interstitiels du HautAtlas occidental: Internationale Revue der Gesamten Hydrobiologie und Hydrographie, v. 80, p. 453-468. https://doi.org/10.1002/iroh. 19950800310.

Delić, T., Trontelj, P., Zakšek, V., and Fišer, C., 2016, Biotic and abiotic determinants of appendage evolution in a cave amphipod: Journal of Zoology, v. 299, p. 42-50.

Ducarme, X., Wauthy, G., André, H.M., and Lebrun, P., 2004, Survey of mites in caves and deep soil and evolution of mites in these habitats: Canadian Journal of Zoology, v. 82, p. 841-850. https://doi.org/10.1139/z04-053.

Environmental Agency 2009. The Hyporheic Handbook: Bristol, England, Environmental Agency, science report SC050070, 264 p. 
Fagan, W.F, Lutscher, F., and Schneider, K., 2007, Population and community consequences of spatial subsidies derived from central-place foraging: American Naturalist, v. 170, p. 902-915. https://doi.org/10.1086/522836.

Fairchild, I.J., and Baker, A., 2012, Speleothem Science. From Process to Past Environments: Chichester, England, Wiley-Blackwell, 432 p.

Fenolio, D., 2016, Life in the Dark. Illuminating Biodiversity in the Shadowy Haunts of Planet Earth: Baltimore, Maryland, Johns Hopkins University Press, $317 \mathrm{p}$.

Fišer, C., Pipan, T., and Culver, D.C., 2014, The vertical extent of groundwater metazoans: an ecological and evolutionary perspective: Bioscience, v. 64, p. 971-979. https://doi.org/10.1093/biosci/biul48.

Fišer, C., Zagmajster, M., and Zakšek, V., 2013, Coevolution of life history traits and morphology in female subterranean amphipods: Oikos, v. 122, p. 770-778. https://doi.org/10.1111/j.1600-0706.2012.20644.x.

Humphreys, W.F., 2001, Groundwater calcrete aquifers in the Australian arid zone: the context to an unfolding plethora of stygal biodiversity: Records of the Western Australian Museum, Supplement, no. 64, p. 63-83.

Hüppop, K., 2000, How do cave animals cope with the food scarcity in caves?, in Wilkens, H., Culver, D.C., and Humphreys, W.H., eds., Subterranean Ecosystems. Amsterdam, The Netherlands, Elsevier, p. 159-188.

Jones, R., Culver, D.C., and Kane, T.C., 1992, Are parallel morphologies of cave organisms the result of similar selection pressures?: Evolution, v. 46, p. 353-365. https://doi.org/10.2307/2409856.

Juberthie, C., Delay, B., and Bouillon, M., 1980, Sur l'existence d'un milieu souterrain superficiel en zone non calcaire: Compte Rendus de l'Académie des Sciences de Paris, v. 290, p. 49-52.

Karaman, S.L., 1954, Über unsere unterirdische fauna: Acta Musei Macedonica Scientiarum Naturalium, v. 1, p. 195-216.

Kingsolver, J.G., and Pfennig, D.W., 2004, Individual-level selection as a cause of Cope's rule of phyletic size increase: Evolution, v. 58, p. 1608 1612. https://doi.org/10.1111/j.0014-3820.2004.tb01740.x.

MacArthur, R.H., and Levins, R., 1967, The limiting similarity, convergence, and divergence of coexisting species: American Naturalist, v. 101, p. 377383.

Malard, F., Ward, J.V., and Robinson, C.T., 2000, An expanded perspective of the hyporheic zone: Verhaltlungen der Internationalen Vereinigung für Theoretische und Angewandte Limnologie, v. 27, p. 431-437.
Meštrov, M., 1962, Un nouveau milieu aquatique souterrain: le biotope hypotelminorhéique: Compte Rendus Academie des Sciences, Paris, v. 254 , p. $2677-2679$.

Ortuño, V.M., Gilgado, J.D., Jiménez-Valverde, A., Sendra, A., Pérez-Suárez, G., and Herrero-Borgoñón, J.J., 2013, The "alluvial mesovoid shallow substratum", a new subterranean habitat: PLOS ONE, v.8, art. 76311, 16 p. https://doi.org/10.1371/journal.pone.0076311.

Pipan, T., and Culver, D.C., 2012, Convergence and divergence in the subterranean realm: a reassessment: Biological Journal of the Linnean Society, v. 107, p. 1-14. https://doi.org/10.1111/j.1095-8312.2012.01964. $\mathrm{x}$.

Racoviţă, E.G., 1907, Essai sur les problèmes biospéologiques: Archives de Zoologie Expérimentale et Générale, v. 6, p. 371-488.

Růžička, V., 1998, The subterranean forms of Lepthyphantes imporbulus, Theonoe minutissima and Theridion bellicosum (Araneae: Linyphiidae, Theridiidae), in Selden, P.A., ed., Edinburgh, Scotland: Proceedings of the $17^{\text {th }}$ European Colloquium of Arachnology, Edinburgh 1997: British Arachnological Society, p. 101-105.

Sendra, A, and Reboleira, A.S.A.S., 2012, The world's deepest subterranean community: Krubera-Voronja Cave (West Caucasus): International Journal of Speleology, v. 41, p. 221-230. https://doi.org/10.5038/ 1827-806X.41.2.9.

Shaw, T.R. 1999. Proteus for sale and for science in the $19^{\text {th }}$ century: Acta Carsologica, v. 28, p. 229-285.

Sibley, R.M., Brown, J.H., and Kodric-Brown, A., eds., 2012, Metabolic Ecology: a Scaling Approach: New York, New York, Wiley-Blackwell, $365 \mathrm{p}$.

Solow, A.R., and Wang, S.C., 2008, Some problems with assessing Cope's rule: Evolution, v. 62, p. 2092-2096. https://doi.org/10.1111/j.1558-5646. 2008.00410.x.

Thibaud, J.M., and Coineau, Y., 1998, Nouvelles stations pour le genre Gordialycus (Acarien: Nematalycidae): Biogeographica, v. 74, p. 91-94.

Trontelj, P., Blejec, A., and Fišer, C., 2012, Ecomorphological convergence in cave communities: Evolution, v. 66, p.3852-3865. https://doi.org/10.1111/ j.1558-5646.2012.01734.x.

Vergnon, R., Leijs, R., van Nes, E.H., and Scheffer, M., 2013, Repeated parallel evolution reveals limiting similarity in subterranean diving beetles: American Naturalist, v. 182, p. 67-75. https://doi.org/10.1086/ 670589 . 